\title{
Evaluation of a short food frequency questionnaire used among Norwegian children
}

\author{
Inger Therese L. Lillegaard'*, Nina Cecilie $\varnothing_{\text {verby }}^{2}$ and \\ Lene Frost Andersen ${ }^{3}$
}

\footnotetext{
'Norwegian Scientific Committee for Food Safety, Oslo, Norway; ${ }^{2}$ Faculty for Health and Sport, Department of Public Health, Sports and Nutrition, University of Agder, Oslo, Norway; ${ }^{3}$ Department of Nutrition, IMB, University of Oslo, Oslo, Norway
}

\section{Abstract}

Objective: The aim of this study was to evaluate a short food frequency questionnaire (FFQ) against a four-day precoded food diary (PFD) with regard to frequency of food intake among Norwegian 9- and 13-year-olds.

Subjects and design: A total of 733 9-year-olds and 904 13-year-olds completed first a short FFQ and one to two weeks later a four-day PFD. The short FFQ included questions about 23 food items, including different drinks, fruits, vegetables, bread, fish, pizza, sweets, chocolate and savoury snacks. The PFD covered the whole diet.

Results: When comparing mean intake from the PFD with comparable food items in the FFQ, all food items showed that increasing intake measured with the PFD corresponded with increasing intake with the short FFQ. However, participants reported a significantly higher frequency of intake for most foods with the short FFQ compared with PFD, except for soft drinks with sugar and sweets. The median Spearman correlation coefficient between the two methods was 0.36 among the 9 -year-olds and 0.32 among the 13 -year-olds. Often eaten foods such as fruits and vegetables had higher correlations than seldom eaten foods such as pizza and potato chips. The median correlation coefficients for drinks alone were higher $(r=0.47)$ for both age groups.

Conclusions: Results indicate that the short FFQ was able to identify high and low consumers of food intake and had a moderate capability to rank individuals according to food intake. Drinks, fruits and vegetables had better correlations with the PFD than infrequently eaten food items.

Keywords: short food frequency questionnaire; evaluation; relative validation; children; adolescents

Received: 17 February 20II; Revised: 8 December 20II; Accepted: 9 December 20II; Published: 16 January 2012

$\mathrm{F}$ jood frequency questionnaires (FFQs) have been used as an epidemiological tool for several decades (1). Many FFQs of variable lengths with primary aims to measure the whole diet have been developed and validated (2-6). However, when a single nutrient or food group is of interest, short FFQs may be enough to assess the intake. Several studies among adults have evaluated short FFQs at the food intake level (7-9), and short FFQs have also been evaluated among children and adolescents (10-18). The advantages of a short questionnaire are the ability to collect data more frequently because it is less expensive than more traditional dietary assessment methods; it is less burdensome for participants to complete; and data processing time is less than what is needed for more extensive dietary assessment methods.
Measuring dietary intakes in children and adolescents is challenging. For example, children may have difficulty remembering quantities, and they are not always able to describe in detail the food they eat (19). Also, the concept of time and estimation of mean frequency of food intake can be problematic for children. The main nutritional challenges among Norwegian children and adolescents are high intakes of sugar and low intakes of fruits and vegetables $(20,21)$. Our intentions in developing a short FFQ were to monitor foods high in fat and sugar, along with fruit and vegetable intake. Both traditionally eaten food items such as wholegrain bread, potatoes and fish for dinner, use of butter on bread, and more modern foods such as pizza and sugar- and non sugar-containing beverages, along with intake of chocolate and sweets, 
fruits and vegetables were included in the questionnaire. Moreover, the FFQ had to be inexpensive, undemanding, able to detect changes on group level and to rank children and adolescents according to food intake.

This article presents the evaluation of a short FFQ developed for use among children and adolescents. The objective of this study was to examine how well the short FFQ corresponded to a four-day precoded food diary (PFD) with regard to frequencies of food intake and mean food intake.

\section{Subjects and methods}

\section{Subjects}

A total of 1,018 9-year-olds ( $4^{\text {th }}$ grade) and 1,181 13-yearolds $\left(8^{\text {th }}\right.$ grade) were invited to take part in a nationally representative dietary survey, UNGKOST-2000. There were 733 9-year-olds and 904 13-year-olds who completed both a short FFQ and a four-day PFD. This corresponds to a participation rate of $74 \%$.

The study protocols were approved by the National Committee for Research Ethics in Norway and the Norwegian Social Science Data Services.

\section{Design}

The data collection was carried out during SeptemberDecember 2000. Students received an invitation letter along with a short FFQ at school approximately two weeks before food recording started. Students and parents who wanted to participate returned informed consent and the short FFQ by mail to the University of Oslo. A nutritionist visited each class and gave oral and written instructions on how the diet should be recorded. Participants received four PFDs and a photographic booklet depicting portion sizes. All participants were phoned on the second day of their recording period to encourage participation and provide answers to questions. Participants were instructed to call the study nutritionist any time if they had questions.

\section{Short food frequency questionnaire}

In the short FFQ, frequency of intake of 23 food items was recorded. Nine questions pertained to drinks: milk (four different fat contents), orange juice, fruit drinks and soft drinks with and without sugar. Furthermore, the FFQ contained questions about each of the following food items or food groups: potatoes, vegetables, fruit/ berries, potato chips, whole meal bread, fish for dinner (not including bread spread), pizza, hamburger/hot dog/ kebab, sweets, chocolate, savoury snacks, peanuts, cod liver oil and vitamin supplements. In addition, one question pertained to the use of butter/margarine on bread. The participants were asked to have in mind their food habits during the last year when filling in the questionnaire.
The short FFQs were filled in at home, and the participants could get help from their parents to complete the questionnaire.

The frequency scale used for drinks were never-seldom, 1-3 glasses per month, 1-3 glasses per week, 4-6 glasses per week, 1-3 glasses per day, 4-6 glasses per day and 7 glasses or more per day. Half a litre was set equal to 3 glasses. For other foods the frequency scales were neverseldom, 1-3 times per month, 1-3 times per week, 4-6 times per week, 1 time per day, 2 times per day, 3 times per day and 4 or more times per day. The question about use of butter-margarine on bread was answered with yes or no.

In the short FFQ, the highest frequencies were rarely reported; therefore, for drinks the frequencies 4-6 glasses per day and 7 glasses or more per day were combined for analyses. For other foods, the frequencies 3 times per day and 4 or more times per day were combined. The questions from the short FFQ about hamburger/hot $\mathrm{dog} / \mathrm{kebab}$ and peanuts were not included in the analyses because these food items were not possible to match with categories from the PFD, and only a few participants reported in the short FFQ that they ate peanuts more often than three times per month.

Besides the food frequency questions the participants were also asked about age, self-reported height and weight, along with parents' education and questions about physical activity and meal patterns.

\section{Precoded food diary}

The participants received one PFD for each day they were to record their food intakes. The 18-page PFD had lists of 277 food items ( 28 drinks, 24 dishes and 255 food items) grouped together according to the typical Norwegian meal pattern (an example of the PFD can be found at the following web site: http://www.med.uio. no/imb/english/research/groups/dietary-research/methods). Each food group was supplemented with open space for food items/dishes not on the list.

Portion size estimations in the PFD were made by household units (e.g. glasses, pieces or tablespoons) or as portions estimated from photographs. Each participant received an evaluated photographic booklet that contained 13 colour photograph series, each with four different photographs ranging from small to large portion sizes (22). The design of the PFD may be viewed as a cross-table, with food listed on the left and time span across the top. Participants indicated an eating event by filling in how many units they had eaten of each food item in the correct time span. Four time spans covered 4 hours each (e.g. 6 a.m.-10 a.m., 10 a.m.-2 p.m.) and one covered 8 hours (10 p.m. 6 a.m.). Participants were instructed to either fill in the PFD immediately after finishing each meal or to record foods eaten on an attached memory note-paper and complete the PFD in the evening. The 13-year-old participants recorded their 
diets themselves, while parents helped the 9-year-olds to fill in the PFDs.

Data were scanned using the Teleform programme (6.0) (Datascan). Daily intake of foods - food groups from the PFD (amounts in grams per day) were computed using the food database and software system (KBS, version 4.7, 2004) at the Department of Nutrition, University of Oslo. The food items from the PFD were also recoded into glasses per day and times per day to allow for a more direct comparison to the frequencies obtained from the short FFQ. For drinks, the amount in grams per day from the PFD was divided by 167 (half a litre equals 3 glasses) to get glasses per day. For foods, the PFD was divided into five time spans during one day, and when a participant indicated to have eaten a food in one time span it was counted as one time per day, independent of the portion size.

\section{$B M R, B M R$-factor and energy under-reporters}

Estimates of basal metabolic rate (BMR) were calculated from standard equations based on height, weight, age and sex (23). The equations for girls and boys aged 4-10 years and 11-18 years were used. The ratio between energy intake and estimates of BMR can be used to calculate the number of participants in a dietary survey who underreport their energy intakes (24). Based on estimates of BMR with $95 \%$ confidence limits, a diet record period of 4 days, and a physical activity level for girls and boys of 1.70 and 1.75 , respectively (23), participants were classified as energy under-reporters when having a ratio between measured energy intake and BMR (EI/BMR) below 1.12 for girls and 1.16 for boys.

\section{Statistics}

Data were analysed using SPSS version 13.0 for Windows. Data from the short FFQ and the PFD were generally skewed; hence, nonparametric statistical methods were mostly chosen. The medians, means, $25^{\text {th }}$ and $75^{\text {th }}$ percentiles are presented. Participant characteristics are presented as means and standard deviation (SD). The food intake reported with the PFD was calculated both in gram per day and frequencies (glasses per day or times per day), and Spearman correlation coefficients were calculated between frequencies from the short FFQ and the PFD for both grams per day and frequencies. The confidence intervals of Spearman correlation coefficients were used to detect differences between girls vs. boys and all participants vs. energy under-reporters. The differences between the two methods were tested using Wilcoxon's signed-rank test. A nonparametric test for ordered groups (25) was used to test whether the short FFQ categories ranked daily intake from the PFD in a specific order. Mann-Whitney test was used to compare intake between participants and non-participants.
To evaluate the butter on bread, cod liver oil and vitamin supplement questions, we calculated the short FFQs specificity and sensitivity compared with the PFD. Specificity for the three items was defined as the number of subjects having answered neither to eat the item in the short FFQ nor recorded the item in the PFD as a percentage of those not having recorded the item according to the PFD. Sensitivity was calculated as the number of those having answered that they ate the food item, with both the short FFQ and the PFD as a percentage of those who had recorded the food item with the PFD.

\section{Results}

Characteristics of the participants are shown in Table 1. The mean intake of food items from the PFD increased with increasing frequency categories from the short FFQ (Tables 2 and 3). Spearman correlation coefficients between the frequency reported from the short FFQ and the amount (grams per day) from the PFD ranged from 0.11 for pizza to 0.67 for low-fat milk among the 9-year-olds, with a median correlation coefficient of 0.36 (Table 2). Among the 13-year-olds, the range was from 0.14 for pizza to 0.63 for low-fat milk, the median correlation coefficient was 0.32 (Table 3 ). The median correlation coefficients for drinks were higher with 0.47 for both age groups. Similar results were found when the data were analysed for gender separately (see additional data Tables 5 and 6).

The short FFQ was also compared with food intake from the PFD recoded into frequencies per day (Tables 5-6), as opposed to grams per day (Tables 2-3). There were no differences in the Spearman correlations, whether food intake with the PFD was coded as frequencies per day or grams per day. However, participants reported a significantly higher frequency of intake for most foods with the short FFQ compared with PFD, except for soft drinks with sugar and sweets, which were reported at levels significantly higher with the PFD for both age groups (Tables 5-6). There were no significant differences between the short FFQ and PFD for soft drinks without sugar, pizza and savoury snacks among both age groups, and for skimmed milk among the 13-year-olds.

Forty-nine 9-year-olds (7\%) and 200 13-year-olds $(24 \%)$ had EI-BMR ratios below the lower cut-off points of 1.12 for girls and 1.16 for boys; these participants are likely to have under-reported their energy intakes during the PFD recording period. The association between frequency of intake reported by the short FFQ and the amount eaten by the PFD was similar whether the underreporters were included or not.

Sensitivity and specificity for intake of butter on bread, cod liver oil and vitamin supplements are presented in Table 4. The sensitivity was high for the three questions in both age groups, while the specificity varied more, with 
Table 1. Participant characteristics

\begin{tabular}{|c|c|c|c|c|}
\hline & \multicolumn{2}{|c|}{ 9-year-olds } & \multicolumn{2}{|c|}{ 13-year-olds } \\
\hline & Girls, mean (SD) & Boys, mean (SD) & Girls, mean (SD) & Boys, mean (SD) \\
\hline Age (years) & $8.9(0.3)^{\mathrm{a}}$ & $8.9(0.3)^{\mathrm{e}}$ & $12.9(0.3)^{i}$ & $12.9(0.3)^{\mathrm{m}}$ \\
\hline Height $(\mathrm{cm})$ & $137(7)^{\mathrm{b}}$ & $137(6)^{f}$ & $16 \mid(7)^{j}$ & $161(9)^{n}$ \\
\hline Weight (kg) & $32(6)^{c}$ & $32(6)^{g}$ & $50(9)^{k}$ & $49(10)^{\circ}$ \\
\hline BMI $\left(\mathrm{kg} / \mathrm{m}^{2}\right)$ & $17.1(2.7)^{d}$ & $17.1(2.5)^{\mathrm{h}}$ & $19.1(2.8)^{1}$ & $18.9(2.8)^{p}$ \\
\hline
\end{tabular}

Due to missing values, the number of participants vary between cells: ${ }^{\mathrm{a}} n=365,{ }^{\mathrm{b}} n=334,{ }^{\mathrm{c}} n=346,{ }^{\mathrm{d}} n=333,{ }^{\mathrm{e}} n=368,{ }^{\mathrm{f}} n=33 \mathrm{I},{ }^{\mathrm{g}} n=344,{ }^{\mathrm{h}} n=327$, i $n=467,{ }^{\mathrm{i}} n=439,{ }^{\mathrm{k}} n=444,{ }^{\mathrm{I}} n=426,{ }^{\mathrm{m}} n=437,{ }^{\mathrm{n}} n=409,{ }^{\circ} n=413,{ }^{\mathrm{P}} n=398$.

the lowest value at $66 \%$ for vitamin supplements among the 13-year-olds.

\section{Discussion}

Several studies have developed and evaluated short FFQs with the aim of collecting data on fat intake, calcium intake or, more often, fruit and vegetable intake among children and adolescents (10-18 years). We are not aware, however, of studies that have evaluated short FFQs with a broader aim of monitoring diet changes in sugar- and fatcontaining foods, fruits, vegetables and more traditionally eaten food items among children and adolescents.

In a validation study, the reference method should be as accurate as possible. The energy intake estimated from the PFD, used as the reference method in the present study, has been validated among 46 9-year-olds (26) and 31 13-year-olds (27) against energy expenditure estimated from a position and activity monitor. It was found that the energy intake was underestimated by around $15-20 \%(26,27)$. In the present study, $7 \%$ of the 9 -year-olds and $24 \%$ of the 13 -year-olds under-reported their energy intakes in the PFD recording period according to the calculated cut-off points. Underreporting may have been caused by omitting some foods or food groups or a general under-reporting of amounts eaten. There are indications among adults that those who grossly under-report their energy intakes tend to underestimate intake of foods believed to be unhealthy (28, 29). Sjöberg et al. (30) did not find systematic misreporting of foods among older adolescents, and neither did Lillegaard and Andersen (26) among 9-year-olds. In the present study, the association between frequency of intake reported by the short FFQ and the amount eaten by the PFD was similar whether under-reporters were included or not.

FFQs cannot be considered to have a global validity. Each item within a questionnaire and any combination of these into complex estimates can be described in terms of their specific validity. This becomes pronounced when looking at Tables 2 and 3. Within the same questionnaire the Spearman correlation coefficient varies from 0.11 for pizza to 0.67 for low-fat milk, among the 9-year-olds.

We found that the mean intake of food items reported by the PFD was increased with increasing quantities reported by short FFQ (Tables 2 and 3). The trend was significant for every food item for both age groups. This indicates that the FFQ can be used to distinguish between low and high consumers.

The present study showed better correlations for drinks than for other food items. It might be that the preferred kinds of milk, soft drinks and fruit drinks are part of a more regular eating practise and are easier for children and adolescents to remember than the other food items asked about in the short FFQ. The number of days required to rank dietary intakes with desired precision varies between different study groups (31) and food items. Several studies have shown that day-to-day variability is high for foods, and usual intake of foods eaten rarely would be very difficult to capture $(31,32)$. Correlation coefficients between the short FFQ and the PFD were mostly in the moderate range. However, the lowest correlations were observed for food items eaten at the lowest frequencies. This could be due to the relatively short recording period of four days.

As mentioned above, several studies have validated short fruit and vegetable questionnaires among children and adolescents $(10,12,14,15)$. In the present study, the short FFQ overestimated the intake of fruit and vegetable compared to PFD. This has also been observed by others $(10,12,16)$. The correlation coefficients found between the short FFQ and the PFD in our study were in the midrange. Andersen et al. (10), also using the PFD as reference method, found correlation coefficients from 0.21 to 0.32 among 11-year-old Norwegians when validating a short FFQ concerning fruits and vegetables. Others $(12,15,16)$ have also found lower correlation coefficients than in the present study. A study by Eriksen (14) showed high correlation for vegetables (0.65) but lower correlation for fruits (0.27).

Results showed a tendency to over-report healthy foods such as low-fat milk, orange juice, boiled potatoes, 
Table 2. (a) Mean intake (g/day) reported by the precoded food diary ranged by glasses per day reported by the FFQ, number of respondents for each FFQ category in parentheses, Spearman correlation coefficients between the two measurements, 9-year-olds, $(n=733)$.

Glasses per month, week and day

\begin{tabular}{|c|c|c|c|c|c|c|c|}
\hline Food item & Never & I-3/month & I-3/week & $46 /$ week & I-3/day & $\geq 4 /$ day $^{\mathrm{a}}$ & Spearman ${ }^{\mathrm{b}}$ \\
\hline Full-fat milk & $9(446)$ & $26(37)$ & $51(36)$ & $105(27)$ & $26 \mid(94)$ & $286(22)$ & $0.66(0.62-0.70)$ \\
\hline Low-fat milk (I.5\% fat) & $43(161)$ & $39(38)$ & $63(45)$ & $124(84)$ & $262(296)$ & 398 (7I) & $0.67(0.63-0.7 I)$ \\
\hline Semi-skim milk ( $0.7 \%$ fat) & 7 (474) & $18(33)$ & $42(32)$ & $64(21)$ & $166(67)$ & $256(9)$ & $0.59\left(\begin{array}{lll}0.54 & 0.64)\end{array}\right.$ \\
\hline Skimmed milk & $7(556)$ & $22(18)$ & $43(13)$ & $88(10)$ & $237(27)$ & - & $0.46(0.40-0.52)$ \\
\hline Orange juice & $7(125)$ & $24(174)$ & $4 \mid(199)$ & $95(95)$ & $|3|(90)$ & $94(6)$ & $0.45(0.39-0.5 I)$ \\
\hline Fruit drink with sugar & $58(78)$ & 70 (7I) & 110 (159) & $128(157)$ & $243(217)$ & $342(26)$ & $0.48(0.42-0.53)$ \\
\hline Fruit drink without sugar & $5(420)$ & I7 (7I) & $28(52)$ & $70(4 I)$ & $162(58)$ & $176(7)$ & $0.47(0.4 \mathrm{I}-0.52)$ \\
\hline Soft drinks with sugar & $106(23)$ & $81(80)$ & $153(40 \mid)$ & $212(185)$ & $333(2 \mathrm{I})$ & $0(2)$ & $0.30(0.23-0.36)$ \\
\hline Soft drinks without sugar & $9(445)$ & $9(96)$ & $39(73)$ & $88(28)$ & $172(5)$ & - & $0.32(0.25-0.38)$ \\
\hline
\end{tabular}

(b) Mean intake ( $\mathrm{g} /$ day) reported by the precoded food diary ranged by times per day reported by the FFQ, number of respondents for each FFQ category in parentheses, Spearman correlation coefficients between the two measurements, 9-year-olds, $(n=733)$.

Times per month, week and day

\begin{tabular}{|c|c|c|c|c|c|c|c|c|}
\hline Food item & Never & $\mathrm{I}-3 /$ month & I-3/week & $46 /$ week & I/day & $2 /$ day & $\geq 3 /$ day $^{a}$ & Spearman ${ }^{\mathrm{b}}$ \\
\hline Potatoes, boiled & $6(20)$ & $14(39)$ & $29(265)$ & 49 (324) & $59(78)$ & - & $53(6)$ & $0.36(0.30-0.42)$ \\
\hline Potato chips & I (16I) & $5(477)$ & II (80) & $0(3)$ & - & - & - & $0.23(0.16-0.30)$ \\
\hline Vegetables & $17(48)$ & $28(68)$ & 39 (224) & $66(224)$ & $80(128)$ & $105(27)$ & $118(8)$ & $0.43(0.37-0.49)$ \\
\hline Fruit and berries & $16(19)$ & $14(36)$ & $59(158)$ & 63 (199) & 89 (189) & $116(94)$ & $164(28)$ & $0.44(0.38-0.50)$ \\
\hline Wholemeal bread & $18(33)$ & $9(20)$ & $21(46)$ & $30(52)$ & $28(8 \mathrm{I})$ & $39(213)$ & $50(277)$ & $0.24(0.17-0.31)$ \\
\hline Fish for dinner & $8(59)$ & $17(204)$ & $27(460)$ & $37(7)$ & $50(1)$ & - & - & $0.25(0.18-0.32)$ \\
\hline Pizza & $16(26)$ & $30(518)$ & $35(186)$ & - & - & - & - & $0.11\left(\begin{array}{lll}0.04 & 0.18)\end{array}\right.$ \\
\hline Sweets & $4(18)$ & 7 (58) & $16(6 \mid 3)$ & $2 I(3 I)$ & $15(10)$ & $5(1)$ & $4(1)$ & $0.21\left(\begin{array}{lll}0.14 & 0.28)\end{array}\right.$ \\
\hline Chocolate & $6(47)$ & $8(133)$ & $14(5 \mid 8)$ & $31(17)$ & $0(2)$ & $12(2)$ & $39(1)$ & $0.19(0.12-0.26)$ \\
\hline Savoury snacks & $3(56)$ & $6(242)$ & $9(420)$ & $2(5)$ & $6(1)$ & - & - & $0.16(0.09-0.23)$ \\
\hline
\end{tabular}

${ }^{\text {a }}$ A non-parametric method was used to test for trend across ordered groups (Altman 199I). There were significant trends for all food items shown in Table 2 ( $P<0.01$ ).

${ }^{\mathrm{b}}$ Spearman correlation coefficients $(95 \%$ confidence interval) 
Table 3. (a) Mean intake (g/day) reported by the precoded food diary ranged by glasses per day reported by the FFQ, number of respondents for each FFQ category in parentheses, Spearman correlation coefficients between the two measurements, 13 -year-olds, $(n=904)$.

Glasses per month, week and day

\begin{tabular}{|c|c|c|c|c|c|c|c|}
\hline Food item & Never & I-3/month & I-3/week & $46 /$ week & $\mathrm{I}-3 /$ day & $\geq 4 /$ day $^{\mathrm{a}}$ & Spearman $^{\mathrm{b}}$ \\
\hline Full-fat milk & $8(646)$ & $33(49)$ & $73(4 I)$ & $55(2 \mathrm{I})$ & $194(70)$ & $243(15)$ & $0.57(0.52-0.61)$ \\
\hline Low-fat milk (I.5\% fat) & $18(232)$ & $40(77)$ & $48(96)$ & $96(132)$ & |9| (248) & $377(77)$ & $0.63(0.59-0.67)$ \\
\hline Semi-skim milk ( $0.7 \%$ fat) & 7 (548) & $22(79)$ & $40(59)$ & $55(46)$ & $139(84)$ & $25 I(26)$ & $0.53(0.48-0.58)$ \\
\hline Skimmed milk & $7(686)$ & $14(45)$ & $24(38)$ & $48(20)$ & $194(23)$ & $287(16)$ & $0.4 I(0.35-0.46)$ \\
\hline Orange juice & $6(139)$ & $20(192)$ & $45(232)$ & $66(157)$ & $136(123)$ & $217(3 \mathrm{I})$ & $0.49\left(\begin{array}{lll}0.44 & 0.54)\end{array}\right.$ \\
\hline Fruit drink with sugar & $55(|3|)$ & $38(115)$ & $90(188)$ & I35 (I83) & $255(187)$ & $308(66)$ & $0.47(0.42-0.52)$ \\
\hline Fruit drink without sugar & $10(506)$ & $16(116)$ & $19(91)$ & $31(56)$ & $169(50)$ & $198(13)$ & $0.33(0.27-0.39)$ \\
\hline Soft drinks with sugar & $127(33)$ & $160(70)$ & $234(300)$ & $300(350)$ & $483(101)$ & $725(24)$ & $0.35(0.29-0.4 \mathrm{I})$ \\
\hline Soft drinks without sugar & $15(557)$ & $34(124)$ & 71 (85) & $47(45)$ & $134(23)$ & $211(8)$ & $0.30(0.240 .36)$ \\
\hline
\end{tabular}

(b) Mean intake ( $g /$ day) reported by the precoded food diary ranged by times per day reported by the FFQ, number of respondents for each FFQ category in parentheses, Spearman correlation coefficients between the two measurements, I3-year-olds, $(n=904)$.

Times per month, week and day

\begin{tabular}{|c|c|c|c|c|c|c|c|c|}
\hline Food item & Never & I-3/month & I-3/week & $46 /$ week & I/day & $2 /$ day & $\geq 3 /$ day $^{\mathrm{a}}$ & Spearman $^{\mathrm{b}}$ \\
\hline Boiled potatoes & $2(15)$ & $22(56)$ & 33 (297) & $49(366)$ & $56(144)$ & 91 (7) & $52(12)$ & $0.26\left(\begin{array}{lll}0.20 & 0.32)\end{array}\right.$ \\
\hline Potato chips & $3(208)$ & 7 (536) & $8(136)$ & $40(\mathrm{II})$ & $0(\mathrm{I})$ & - & $0(\mathrm{I})$ & $0.15(0.09-0.21)$ \\
\hline Vegetables & $30(85)$ & $28(95)$ & 48 (297) & $63(222)$ & $80(15 I)$ & $103(24)$ & $109(22)$ & $0.32(0.26-0.38)$ \\
\hline Fruit and berries & $22(47)$ & $32(90)$ & $39(258)$ & $55(204)$ & $80(163)$ & $89(78)$ & $114(55)$ & $0.31(0.25-0.37)$ \\
\hline Wholemeal bread & $8(67)$ & $12(52)$ & I5 (I2I) & $23(101)$ & $37(110)$ & 4I (192) & $60(244)$ & $0.33(0.27-0.39)$ \\
\hline Fish for dinner & $8(105)$ & $16(367)$ & $29(392)$ & $40(22)$ & - & $47(5)$ & - & $0.26(0.20-0.32)$ \\
\hline Pizza & $18(32)$ & $43(552)$ & $53(287)$ & $118(17)$ & $49(2)$ & - & $68(I)$ & $0.14(0.08-0.20)$ \\
\hline Sweets & $4(3 I)$ & $10(71)$ & 18 (579) & $28(138)$ & $29(53)$ & $28(15)$ & $44(9)$ & $0.26(0.20-0.32)$ \\
\hline Chocolate & $8(56)$ & $12(168)$ & $19(539)$ & $29(83)$ & 34 (34) & $26(9)$ & $65(3)$ & $0.24(0.18-0.30)$ \\
\hline Savoury snacks & 7 (78) & $12(232)$ & $16(506)$ & $27(48)$ & $21(20)$ & $95(5)$ & - & $0.21(0.15-0.27)$ \\
\hline
\end{tabular}

${ }^{a}$ A non-parametric method was used to test for trend across ordered groups (Altman 199I). There were significant trends for all food items shown in Table 3 ( $P<0.01$ ).

${ }^{\mathrm{b}}$ Spearman correlation coefficients ( $95 \%$ confidence interval) 
Table 4. Sensitivity and specificity of the short food frequency questionnaire for use of butter on bread, cod liver oil and vitamin supplements

\begin{tabular}{llcc}
\hline & & Sensitivity (\%) & Specificity (\%) \\
\hline 9-year-olds & Butter on bread & 89 & 72 \\
& Cod liver oil & 87 & 83 \\
& Vitamin supplements & 79 & 73 \\
13-year-olds & Butter on bread & 82 & 69 \\
& Cod liver oil & 76 & 83 \\
& Vitamin supplements & 84 & 66 \\
\hline
\end{tabular}

wholemeal bread, fruits and vegetables in the short FFQ compared with the PFD, and this tendency was the same for both age groups. Two food items regarded as unhealthy, namely soft drinks with sugar and sweets, were significantly under-reported with the short FFQ compared to the PFD.

The sensitivity for the three questions, 'butter on bread', cod liver oil and vitamin supplements, were high. Those who normally consume these food items also consumed them during the four-day recording period. The 'butter on bread' question was phrased: Do you normally use butter on bread? In this case, over- reporting could have occurred because those who did not habitually use butter on bread may have used butter once or twice during the four-day recording period, thereby being coded in the wrong category.

Questions have been raised whether FFQs asking about usual intake are suitable for children $(17,19)$ because they require abstract thinking, knowledge about food names and food grouping, as well as basic reading and arithmetic skills. This may be too advanced for 9year-olds, as well as young adolescents who may have problems filling in a longer FFQ (33). In the present study, the short FFQ had few questions and was completed at home. There were only small differences in correlations between the two age groups studied, where the 9-year-olds showed slightly higher correlation coefficients compared to the 13-year-olds. Both age groups had the opportunity to complete the short FFQ together with their parents, but the 13-year-olds may have completed more of the questionnaire themselves compared to the 9 -year-olds.

\section{Conclusion}

Results indicate that the short FFQ was able to identify low and high consumers of food intake and had a moderate capability to rank individuals according to food intake. Intake of drinks, fruits and vegetables

Table 5. Intake in glasses or times per day with the short food frequency questionnaire (FFQ) and with the precoded food diary (PFD) among 9-year-olds, $n=733$, median $(\mathrm{P} 25, \mathrm{P} 75)^{\mathrm{a}}$, mean

\begin{tabular}{|c|c|c|c|c|}
\hline Food item & Short FFQ & PFD & $p^{\mathrm{b}}$ & Spearman $^{c}$ \\
\hline Full fat milk & $0(0,0.07) 0.46$ & $0(0,0.22) 0.34$ & 0.02 & $0.63(0.58-0.67)$ \\
\hline Low fat milk ( $1.5 \%$ fat) & $2.00(0,2.00) \quad 1.42$ & $0.79(0,1.69) \quad 1.07$ & $<0.001$ & $0.66(0.62-0.70)$ \\
\hline Semi-skim. milk ( $0.7 \%$ fat) & $0(0,0) 0.28$ & $0(0,0) 0.17$ & $<0.001$ & $0.57(0.52-0.62)$ \\
\hline Skimmed milk & $0(0,0) 0.09$ & $0(0,0) 0.12$ & 0.001 & $0.42(0.36-0.48)$ \\
\hline Orange juice & $0.29(0.07,0.7 I) 0.48$ & $0(0,0.34) 0.29$ & $<0.001$ & $0.44(0.38-0.50)$ \\
\hline Fruit drink with sugar & $0.7 \mid(0.29,2.00) 1.00$ & $0.67(0,1.36) 0.89$ & 0.03 & $0.50\left(\begin{array}{lll}0.44 & 0.55)\end{array}\right.$ \\
\hline Fruit drink without sugar & $0(0,0.07) 0.28$ & $0(0,0) 0.16$ & $<0.001$ & $0.44(0.38-0.50)$ \\
\hline Soft drinks with sugar & $0.29(0.29,0.7 I) 0.42$ & $0.75(0.34,1.40) 0.97$ & $<0.001$ & $0.30(0.23-0.36)$ \\
\hline Soft drinks without sugar & $0(0,0.07) 0.08$ & $0(0,0) 0.10$ & 0.88 & $0.30(0.23-0.36)$ \\
\hline Boiled potatoes & $0.7 I(0.29,0.7 I) 0.56$ & $0.25(0,0.50) 0.30$ & $<0.001$ & $0.32(0.25-0.38)$ \\
\hline Potato chips & $0.07(0.07,0.07) 0.08$ & $0(0,0) 0.05$ & $<0.001$ & $0.22(0.15-0.29)$ \\
\hline Vegetables (fresh) & $0.7 I(0.29,0.7 I) 0.60$ & $0.25(0,0.75) 0.40$ & $<0.001$ & $0.50\left(\begin{array}{lll}0.44 & 0.55)\end{array}\right.$ \\
\hline Fruit (fresh) & $0.71(0.29,1.00) 0.90$ & $0.50(0.25,1.00) 0.72$ & $<0.001$ & $0.45(0.39-0.5 \mathrm{I})$ \\
\hline Wholemeal bread & $2.00(1.00,3.00) 1.93$ & $1.50(1.00,2.25) 1.60$ & $<0.001$ & $0.26(0.19-0.33)$ \\
\hline Fish for dinner & $0.29(0.07,0.29) 0.21$ & $0.25(0,0.25) 0.17$ & $<0.001$ & $0.24(0.17-0.31)$ \\
\hline Pizza & $0.07(0.07,0.29) 0.12$ & $0(0,0.25) 0.16$ & 0.14 & $0.10(0.03-0.17)$ \\
\hline Sweets & $0.29(0.29,0.29) 0.30$ & $0.50(0.25,0.75) 0.56$ & $<0.001$ & $0.20(0.13-0.27)$ \\
\hline Chocolate & $0.29(0.07,0.29) 0.25$ & $0.25(0,0.25) 0.22$ & $<0.001$ & $0.17(0.10-0.24)$ \\
\hline Savoury snacks & $0.29(0.07,0.29) 0.20$ & $0.25(0,0.25) 0.23$ & 0.59 & $0.15(0.08-0.22)$ \\
\hline
\end{tabular}

${ }^{\text {a }} \mathrm{P} 25=25^{\text {th }}$ percentile, $\mathrm{P} 75=75^{\text {th }}$ percentile.

b Wilcoxon signed rank test.

c Spearman correlation coefficients ( $95 \%$ confidence interval). 
Table 6. Intake in glasses or times per day with the short food frequency questionnaire (FFQ) and with the precoded food diary (PFD) among 13-year-olds, $n=904$, median $(\mathrm{P} 25, \mathrm{P} 75)^{\mathrm{a}}$, mean

\begin{tabular}{|c|c|c|c|c|}
\hline Food item & Short FFQ & PFD & $p^{\mathrm{b}}$ & Spearman $^{c}$ \\
\hline Full fat milk & $0(0,0) 0.28$ & $0(0,0) 0.21$ & 0.005 & $0.54(0.49-0.58)$ \\
\hline Low fat milk (I.5\% fat) & $0.71(0,2.00)$ I.I5 & $0.22(0,1.02) 0.69$ & $<0.001$ & $0.6 \mathrm{I}(0.57-0.65)$ \\
\hline Semi-skim. milk ( $0.7 \%$ fat) & $0(0,0.07) 0.4 \mathrm{I}$ & $0(0,0) 0.20$ & $<0.001$ & $0.52(0.47-0.57)$ \\
\hline Skimmed milk & $0(0,0) 0.18$ & $0(0,0) 0.11$ & 0.09 & $0.38(0.32-0.43)$ \\
\hline Orange juice & $0.29(0.07,0.7 I) 0.68$ & $0(0,0.45) 0.33$ & $<0.001$ & $0.48(0.43-0.53)$ \\
\hline Fruit drink with sugar & $0.29(0.07,2.00) \quad 1.04$ & $0.45(0,1.24) 0.83$ & 0.003 & $0.46(0.4 I-0.5 I)$ \\
\hline Fruit drink without sugar & $0(0,0.07) 0.27$ & $0(0,0) 0.15$ & $<0.001$ & $0.32(0.26-0.38)$ \\
\hline Soft drinks with sugar & $0.7 \mid(0.29,0.7 I) 0.75$ & I.38 $(0.67,2.46) \quad 1.75$ & $<0.001$ & $0.33(0.27-0.39)$ \\
\hline Soft drinks without sugar & $0(0,0.07) 0.17$ & $0(0,0) 0.18$ & 0.90 & $0.29(0.23-0.35)$ \\
\hline Boiled potatoes & $0.7 \mathrm{I}(0.29,0.7 \mathrm{I}) 0.6 \mathrm{I}$ & $0.25(0,0.50) 0.25$ & $<0.001$ & $0.30\left(\begin{array}{lll}0.24 & 0.36\end{array}\right)$ \\
\hline Potato chips & $0.07(0.07,0.07) 0.10$ & $0(0,0) 0.06$ & $<0.001$ & $0.15(0.09-0.21)$ \\
\hline Vegetables (fresh) & $0.29(0.29,0.7 I) 0.58$ & $0.25(0,0.50) 0.28$ & $<0.001$ & $0.33(0.27-0.39)$ \\
\hline Fruit (fresh) & $0.71(0.29,1.00) 0.80$ & $0.25(0,0.75) 0.49$ & $<0.001$ & $0.31(0.25-0.37)$ \\
\hline Wholemeal bread & $1.00(0.29,3.00) 1.56$ & $1.25(0.75,1.75) \quad 1.25$ & $<0.001$ & $0.35(0.29-0.4 \mathrm{I})$ \\
\hline Fish for dinner & $0.07(0.07,0.29) 0.18$ & $0(0,0.25) 0.13$ & $<0.001$ & $0.24(0.18-0.30)$ \\
\hline Pizza & $0.07(0.07,0.29) 0.15$ & $0(0,0.25) 0.16$ & 0.92 & $0.14(0.08-0.20)$ \\
\hline Sweets & $0.29(0.29,0.29) 0.43$ & $0.50(0.25,1.00) 0.73$ & $<0.001$ & $0.20\left(\begin{array}{lll}0.14 & 0.26)\end{array}\right.$ \\
\hline Chocolate & $0.29(0.07,0.29) 0.32$ & $0.25(0,0.50) 0.27$ & $<0.001$ & $0.22(0.16-0.28)$ \\
\hline Savoury snacks & $0.29(0.07,0.29) 0.25$ & $0.25(0,0.50) 0.29$ & 0.90 & $0.21(0.15-0.27)$ \\
\hline
\end{tabular}

${ }^{\text {a }} \mathrm{P} 25=25^{\text {th }}$ percentile, $\mathrm{P} 75=75^{\text {th }}$ percentile.

${ }^{b}$ Wilcoxon signed rank test.

c Spearman correlation coefficients ( $95 \%$ confidence interval).

reported in the short FFQ had better correlations with intake recorded in the PFD than did food items eaten less frequently.

\section{Conflict of interest and funding}

This study has partly been financially supported by the Norwegian Extra Foundation for Health and Rehabilitation through EXTRA funds. The authors declare no conflict of interest.

\section{References}

1. Willett WC. Food-frequency methods. In: Willett W, ed. Nutritional epidemiology. Oxford: Oxford University Press; 1998. p. 74-100.

2. Andersen LF, Nes M, Lillegaard IT, Sandstad B, Bjorneboe GE, Drevon CA. Evaluation of a quantitative food frequency questionnaire used in a group of Norwegian adolescents. Eur J Clin Nutr 1995; 49: 543-54.

3. Rockett HR, Breitenbach M, Frazier AL, Witschi J, Wolf AM, Field AE, et al. Validation of a youth/adolescent food frequency questionnaire. Prev Med 1997; 26: 808-16.

4. Subar AF, Thompson FE, Kipnis V, Midthune D, Hurwitz P, McNutt S, et al. Comparative validation of the Block, Willett, and National Cancer Institute food frequency questionnaires: the Eating at America's Table Study. Am J Epidemiol 2001; 154: 1089-99.
5. Schatzkin A, Kipnis V, Carroll RJ, Midthune D, Subar AF, Bingham S, et al. A comparison of a food frequency questionnaire with a 24-hour recall for use in an epidemiological cohort study: results from the biomarker-based Observing Protein and Energy Nutrition (OPEN) study. Int J Epidemiol 2003; 32: 1054-62.

6. Ambrosini GL, de Klerk NH, O'Sullivan TA, Beilin LJ, Oddy WH. The reliability of a food frequency questionnaire for use among adolescents. Eur J Clin Nutr 2009; 63: 1251-9.

7. Osler M, Heitmann BL. The validity of a short food frequency questionnaire and its ability to measure changes in food intake: a longitudinal study. Int J Epidemiol 1996; 25: 1023-9.

8. Thompson FE, Subar AF, Smith AF, Midthune D, Radimer KL, Kahle LL, et al. Fruit and vegetable assessment: performance of 2 new short instruments and a food frequency questionnaire. J Am Diet Assoc 2002; 102: 1764-72.

9. Andersen LF, Johansson L, Solvoll K. Usefulness of a short food frequency questionnaire for screening of low intake of fruit and vegetable and for intake of fat. Eur J Public Health 2002; 12: $208-13$.

10. Andersen LF, Bere E, Kolbjornsen N, Klepp KI. Validity and reproducibility of self-reported intake of fruit and vegetable among 6th graders. Eur J Clin Nutr 2004; 58: 771-7.

11. Van Assema P, Brug J, Ronda G, Steenhuis I. The relative validity of a short Dutch questionnaire as a means to categorize adults and adolescents to total and saturated fat intake. J Hum Nutr Diet 2001; 14: 377-90.

12. Van Assema P, Brug J, Ronda G, Steenhuis I, Oenema A. A short dutch questionnaire to measure fruit and vegetable intake: relative validity among adults and adolescents. Nutr Health 2002; 16: 85-106. 
13. Cullen KW, Baranowski T, Baranowski J, Hebert D, de Moor C. Pilot study of the validity and reliability of brief fruit, juice and vegetable screeners among inner city African-American boys and 17 to 20-year-old adults. J Am Coll Nutr 1999; 18: 442-50.

14. Eriksen K. Developing and evaluation of a method for measuring changes in intake of fruit and vegetable among children aged 6-10 years. Copenhagen (in Danish): Institute for human nutrition; 2010.

15. Domel SB, Baranowski T, Davis H, Leonard SB, Riley P, Baranowski J. Fruit and vegetable food frequencies by fourth and fifth grade students: validity and reliability. J Am Coll Nutr 1994; 13: 33-9.

16. Baranowski T, Smith M, Baranowski J, Wang DT, Doyle C, Lin LS, et al. Low validity of a seven-item fruit and vegetable food frequency questionnaire among third-grade students. J Am Diet Assoc 1997; 97: 66-8.

17. Field AE, Peterson KE, Gortmaker SL, Cheung L, Rockett H, Fox MK, et al. Reproducibility and validity of a food frequency questionnaire among fourth to seventh grade inner-city school children: implications of age and day-to-day variation in dietary intake. Public Health Nutr 1999; 2: 293-300.

18. Harnack LJ, Lytle LA, Story M, Galuska DA, Schmitz L, Jacobs DR Jr. et al. Reliability and validity of a brief questionnaire to assess calcium intake of middle-school-aged children. J Am Diet Assoc 2006; 106: 1790-5.

19. Livingstone MB, Robson PJ. Measurement of dietary intake in children. Proc Nutr Soc 2000; 59: 279-93.

20. Andersen LF, Overby N, Lillegaard IT. Intake of fruit and vegetables among Norwegian children and adolescents. Tidsskr Nor Laegeforen 2004; 124: 1396-8.

21. Overby NC, Lillegaard IT, Johansson L, Andersen LF. High intake of added sugar among Norwegian children and adolescents. Public Health Nutr 2004; 7: 285-93.

22. Lillegaard IT, Overby NC, Andersen LF. Can children and adolescents use photographs of food to estimate portion sizes? Eur J Clin Nutr 2005; 59: 611-7.

23. Nordic Nutriton Recommendations. Integrating nutrition and physical activity. Norden: Nordic Council of Ministers; 2004.

24. Black AE. Critical evaluation of energy intake using the Goldberg cut-off for energy intake:basal metabolic rate. A practical guide to its calculation, use and limitations. Int $\mathbf{J}$ Obes Relat Metab Disord 2000; 24: 1119-30.

25. Altman DG. Non-parametric test for ordered groups. In: Practical statistics for medical research. London: Chapman and Hall; 1991. p. 215-7.

26. Lillegaard IT, Andersen LF. Validation of a pre-coded food diary with energy expenditure, comparison of under-reporters v. acceptable reporters. Br J Nutr 2005; 94: 998-1003.

27. Andersen LF, Pollestad ML, Jacobs DR Jr, Lovo A, Hustvedt BE. Validation of a pre-coded food diary used among 13-yearolds: comparison of energy intake with energy expenditure. Public Health Nutr 2005; 8: 1315-21.

28. Johansson L, Solvoll K, Bjorneboe GE, Drevon CA. Under- and overreporting of energy intake related to weight status and lifestyle in a nationwide sample. Am J Clin Nutr 1998; 68: 266-74.

29. Krebs-Smith SM, Graubard BI, Kahle LL, Subar AF, Cleveland LE, Ballard-Barbash R. Low energy reporters vs others: a comparison of reported food intakes. Eur J Clin Nutr 2000; 54: 281-7.

30. Sjoberg A, Slinde F, Arvidsson D, Ellegard L, Gramatkovski E, Hallberg L, et al. Energy intake in Swedish adolescents: validation of diet history with doubly labelled water. Eur J Clin Nutr 2003; 57: 1643-52.

31. Nelson M, Black AE, Morris JA, Cole TJ. Between- and withinsubject variation in nutrient intake from infancy to old age: estimating the number of days required to rank dietary intakes with desired precision. Am J Clin Nutr 1989; 50: 155-67.

32. Palaniappan U, Cue RI, Payette H, Gray-Donald K. Implications of day-to-day variability on measurements of usual food and nutrient intakes. J Nutr 2003; 133: 232-5.

33. Andersen LF, Nes M, Bjorneboe GEAa, Drevon CA. Food habits among 13-year-old Norwegian adolescents. Scand J Nutr 1997; 41: 150-4.

*Inger Therese L. Lillegaard

Norwegian Scientific Committee for Food Safety

Postboks 4404 Nydalen, 0403 Oslo, Norway

Email: Inger.Therese.Laugsand.Lillegaard@vkm.no 